\title{
Bacterial profile and antimicrobial susceptibility patterns of otitis media in health care centre, southern Trivandrum, Kerala, India
}

\author{
Jobin $\mathrm{S} \mathrm{R}^{1^{*}}$, J W Prakash${ }^{2}$, Jagatheeswary P A T ${ }^{3}$, Rema Devi $\mathrm{S}^{4}$, Subitha $\mathrm{S}^{5}$, L Suresh Babu ${ }^{6}$ \\ Kiran Gopal 7 , Bewin Oral J ${ }^{8}$, P S Aanie ${ }^{9}$
}

\begin{abstract}
${ }^{1}$ Assistant Professor, 4,6,7,8 Department of Microbiology, Dr. Somervell Memorial C.S.I. Medical College, Karakonam, Trivandrum, Kerala, INDIA 695504.

${ }^{2}$ Adjunct Associate Professor, Martin Luther Christian University, Shillong, INDIA. and Hon. Associate Scientist, Environmental Resource Research Centre, Mahatma Gandhi University, Kerala \& Project Co Ordinator Dr. Somervell Memorial C.S.I. Medical College, Karakonam, Trivandrum, Kerala, INDIA.

${ }^{3}$ Professor, Department of Microbiology, Saveetha Medical College, Saveetha University, Chennai, Tamil Nadu, INDIA.

5,9 Research Scholar, Manonmaniam Sundaranar University, Tirunelveli, Tamil Nadu, INDIA.

Email: jobinsr2017@gmail.com
\end{abstract}

Abstract Background: Ear infection is a common problem for both children and adults particularly in developing countries. Thus this study aimed to identify bacterial isolates and determine their drug susceptibility pattern from patients who had ear infection. Cross sectional study was carried out on patients with ear infection from January 2019 to September 2019. For this study 37 samples were collected from patients in the rural area of Trivandrum, Kerala. In this study, pathogens were isolated from 29 (78.37\%) patients out of 37.Staphylococcus aureus 5 (17.24\%), Proteus mirabilis 2 (6.89\%), Pseudomonas aeruginosa 15 (51.72\%) Klebsiella pneumoniae $6(20.68 \%)$ and Escherichia coli 1 (3.44\%) were the bacterial isolate respectively. The Gram negative bacteria were more dominant than Gram positive. The Staphylococcus aureus isolated were resistant to Penicillin (100\%) Erythromycin (80\%) Clindamycin (60\%), Amoxicillin clavulanic acid $(60 \%)$ and Gentamicin (20\%). The Pseudomonas aeruginosa were resistant to Aminoglycosides (13.33 \%). The organism Proteus mirabilis shows $100 \%$ sensitivity towards Amoxicillin clavulanic acid, Gentamicin, Amikacin, Cefazolin, Cefuroxime, Cefotaxime, Ciprofloxacin, Co-trimoxazole, Piperacillintazobactum, Cefaperazonesulbactum. Escherichia coli isolates showed $100 \%$ resistance to Ampicillin, Amoxicillin clavulanic acid, Cefazolin and Cefuroxime. Klebsiella pneumoniae isolates have shown resistance to Amoxicillin clavulanic acid (16.66\%), Gentamicin (33.33\%), Amikacin (33.33\%), Cefazolin (33.33\%), Cefuroxime (33.33\%), Cefotaxime (33.33\%) and Piperacillintazobactum (16.66 \%). Early treatment of ear infection can play great role in management of otitis media and avoid emergence of multi drugresistant bacteria.

Key words: Bacteria, Otitis Media, Antimicrobial Susceptibility.

\section{*Address for Correspondence:}

Mr Jobin S.R, Assistant Professor, Department of Microbiology, Dr. Somervell Memorial C.S.I. Medical College, Karakonam, Trivandrum, Kerala, India.695504 And Ph.D. Scholar, Saveetha University, Chennai, Tamil Nadu, INDIA.

Email: jobinsr2017@gmail.com

Received Date: 10/10/2019 Revised Date: 12/12/2019 Accepted Date: 28/01/2020

DOI: https://doi.org/10.26611/10081411

\begin{tabular}{|l|l|}
\hline \multicolumn{2}{|c|}{ Access this article online } \\
\hline Quick Response Code: & Website: \\
& www.medpulse.in \\
& \\
\hline
\end{tabular}

Ear infection is a common clinical problem throughout the world and the major cause of preventable hearing loss in the developing world (Ullauri et al., 2014). Ear infection which can be classified into Otitis Media (OM) and Otitis Externa, is a major public health concern in developing countries. (Monasta et al.., 2012)Otitis media (OM) is a general term for the expression of infections with various complications in the middle-ear region. OM is divided into three categories: acute OM, OM with effusion, and Chronic Suppurative OM (CSOM) (Gates et al., 2002). The CSOM condition occurs as asequelae to inadequately treated acute otitis media causing persistent 
perforation in the tympanic membrane which could be infected from bacteria in the external auditory canal (Jyothi et al.., 2017).Globally, about 65-330 million people suffer from ear infection and $60 \%$ of them had significant hearing impairment (Woodfield and Dugdale, 2008). The causative agents of ear infection might be bacterial, viral, or fungal. However, the major causative agents of ear infection are bacterial isolates such as Pseudomonas aeruginosa, Escherichia coli, Staphylococcus aureus, Streptococcus pyogenes, Proteus mirabilis, Klebsiella spp., or mixed bacterial infection (Afolabi et al.., 2012). Development and spread of resistant bacteria due to the over and indiscriminate use of antibiotics was a global public health threat.(Spellberg et al..,2008).Due to the limited laboratory diagnosis in developing countries, physicians are often forced to syndromatic diagnosis and prescription of broad spectrum antibiotics for most infections that led to emergence of drug resistant bacterial strains (Lee et al.. 2012). Hence, current information on microbial resistance and the prevalence of the pathogenic bacteria needs to be available at national and local levels to guide the rational use of the existing antimicrobials. In Kerala, few studies reported high prevalence of ear infection and multi drug resistance to the commonly prescribed antibiotics for treatment of ear infection (Muluye et al. 2013) However, there is no published data from study area on the prevalence and antimicrobial susceptibility pattern of bacterial pathogens causing Otitis Media. Hence, current information on prevalence of pathogenic bacteria and their susceptibility pattern must be available at national and local levels to guide the rational use of the existing antimicrobials.

\section{METHODOLOGY}

A cross-sectional study was conducted at health care center Trivandrum, Kerala. Patients who visited the ENT clinic of the hospital with otitis media from January 2019 to September 2019 were consecutively enrolled into the study. A total of 37 ear discharges samples were collected by Otorhinolaryngologist using sterile cotton swabs. Specimens were inoculated directly on Blood agar, Chocolate agar and MacConkey agar following the standard procedure of inoculating culture media. Isolates were identified by colony morphology, Gram staining, Catalase test, Coagulase test, Oxidase test, Triple Sugar Iron agar (TSI), Citrate utilization test, Urease test, Mannitol Motility, Indole and Optochin test (Cheesbrough 2006). Antimicrobial sensitivity test (AST) was done on Mueller Hinton agar (Microxpress, A Division of Tulip Diagnostics (P) Ltd.India) by the Kirby-Bauer technique according to the CLSI guidelines (CLSI-2007) using Escherichia coli (ATCC 25922), Staphylococcus aureus (ATCC 25923) and Pseudomonas aeruginosa (ATCC 27853) as control strains. The antibiotic discs used for the AST included: Ampicillin (10mcg), Cefazolin (30mcg), Amikacin (30 mcg), Amoxycillin/clavulanic acid $(20 / 10 \mathrm{mcg})$, Cefotaxime (30 mcg), Cefuroxime (30 mcg), Ceftazidime (30 mcg), PiperacillinTazobactum ( $100 / 10 \mathrm{mcg})$, Gentamicin (10mcg), Cephoperazone + sulbactam $(75 / 10 \mathrm{mcg})$, Cotrimoxazole $(1.25 / 23.75 \mathrm{mcg})$, Ciprofloxacin $(5 \mathrm{mcg})$, Linezolid $(30 \mathrm{mcg})$, Meropenem $(10 \mathrm{mcg})$, Norfloxacin (10 mcg), Cloxacillin (1 mcg), Tobramycin $(10 \mathrm{mcg})$ Netilmicin, Tetracycline and Vancomycin $(30 \mathrm{mcg})$ from Microxpress, A Division of Tulip Diagnostics (P) Ltd. India.

\section{RESULTS}

The age range of participants for this study was from all age groups. For this analysis 37 samples were collected. They were from the rural areas of Trivandrum, Kerala. In this study, pathogens were isolated from 29 (78.37\%) patients out of 37 . The study was conducted among both males and females. Among the total number of patients 18 $(62.06 \%)$ were males and $11(37.93 \%)$ were females (Table1.). The highest percentage of isolates were reported in below 10 years $(62.06 \%)$ and followed by $71-80$ (20.68\%) (Table. 2.). The highest number of patients were reported during February 5 (17.24\%) and followed by May and July 4 (13.79) (Table. 3.).Staphylococcus aureus 5 (17.24\%), Proteus mirabilis 2 (6.89\%), Pseudomonas aeruginosa 15 (51.72\%) Klebsiella pneumoniae 6 (20.68 $\%)$ and Escherichia coli 1 (3.44\%) were the bacterial isolates respectively (Fig.1). The Gram negative bacteria $24(82.75 \%)$ were more predominant than Gram positive 5 $(17.24 \%)$. In vitro antibiotic susceptibility of Gram positive bacterial isolates were experimented. From the isolates Staphylococcus aureus was the only one reported as Gram positive bacteria and were resistant to Penicillin $(100 \%)$ Erythromycin (80 \%) Clindamycin (60\%), Amoxicillin clavulanic acid $(60 \%)$ and Gentamicin $(20 \%)$.The isolates were all sensitive to Cloxacillin, Cefazolin, Cefuroxime, Co-trimoxazole, Linezolid and Vancomycin shown $100 \%$ sensitivity (Fig.2). The Pseudomonas aeruginosa was resistant to Aminoglycosides (13.33 \%). The Fluoroquinolone Ciprofloxacin shows $13.33 \%$ resistance. Ceftazidime, Piperacillintazobactum and Meropenem showed $100 \%$ sensitivity (Fig.3).The organism Proteus mirabilis shows $100 \%$ sensitivity towards Amoxicillin clavulanic acid, gentamicin, Amikacin, Cefazolin, Cefuroxime, Cefotaxime, Ciprofloxacin, Co-trimoxazole, Piperacillintazobactum, Cefaperazonesulbactum and Meropenem (Fig.4). Escherichia coli showed 100\% resistance to Ampicillin, Amoxicillin clavulanic acid, Cefazolin, and Cefuroxime. Whereas, Cefotaxime, 
Gentamicin, Amikacin, Ciprofloxacin, Co-trimoxazole, Piperacillintazobactum, Cefaperazonesulbactum and Meropenum were $100 \%$ sensitive (Fig.5). Klebsiella pneumonia have shown resistance to Amoxicillin clavulanic acid (16.66 \%), Gentamicin (33.33\%), Amikacin (33.33\%), Cefazolin (33.33\%), Cefuroxime (33.33\%), Cefotaxime (33.33\%) and Piperacillin tazobactum (16.66\%) (Fig.6).

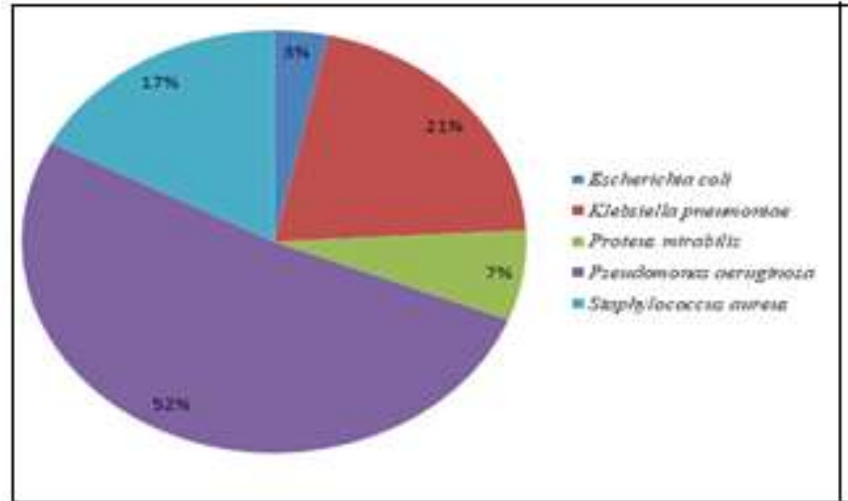

Figure 1: Pathogens isolated from otitis media patients Penicillin CX-Cloxacillin, CZ-Cefazolin, CXM-Cefuroxime Erythromycin,CD-Clindamycin,LZ-Linezolid,VA-Vancomycin

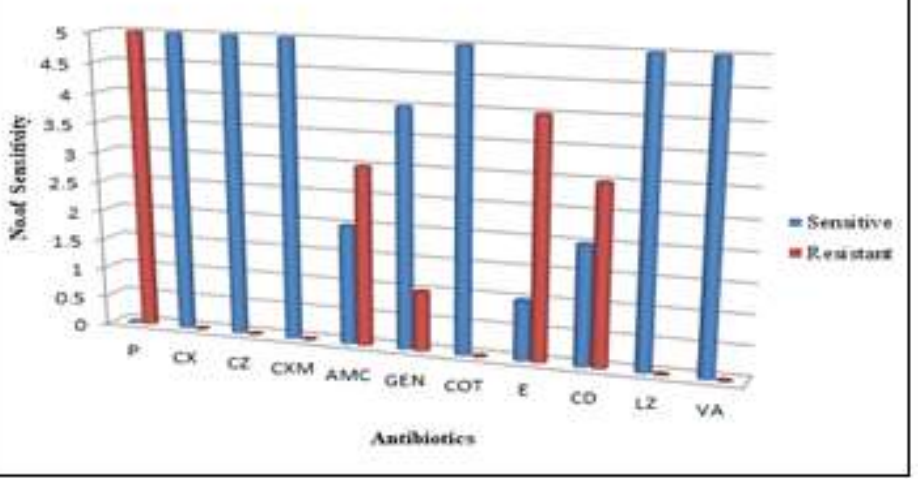

Figure 2: Antibiogram of Staphylococcus aureus AMC-Amoxycillin/clavulanic acid,GEN-Gentamicin, COT-Cotrimoxazole,E-

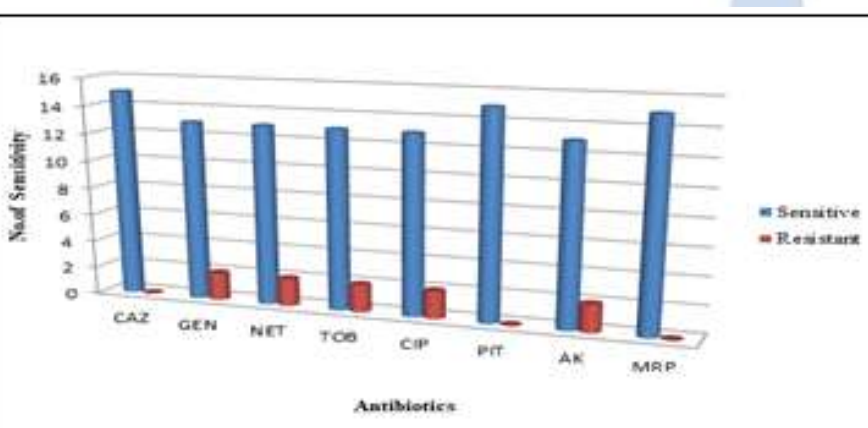

Figure 3: Antibiogram of Pseudomonas aeruginosa CAZ- Ceftazidime, GEN- Gentamicin, NET- Netilmicin, TOB- Tobramycin, CIP- Ciprofloxacin, PIT- PiperacillinTazobactum, AK- Amikacin, MRPMeropenem

AMP-Ampicillin, AMC-Amoxycillin/clavulanic acid, CZ- Cefazolin, CXM-Cefuroxime, CTX-Cefotaxime, CIP-Ciprofloxacin,COT- Cotrimoxazole, GEN- Gentamicin, AK-Amikacin, PIT- PiperacillinTazobactum, CFS- Cephoperazone + sulbactam, MRP- Meropenem

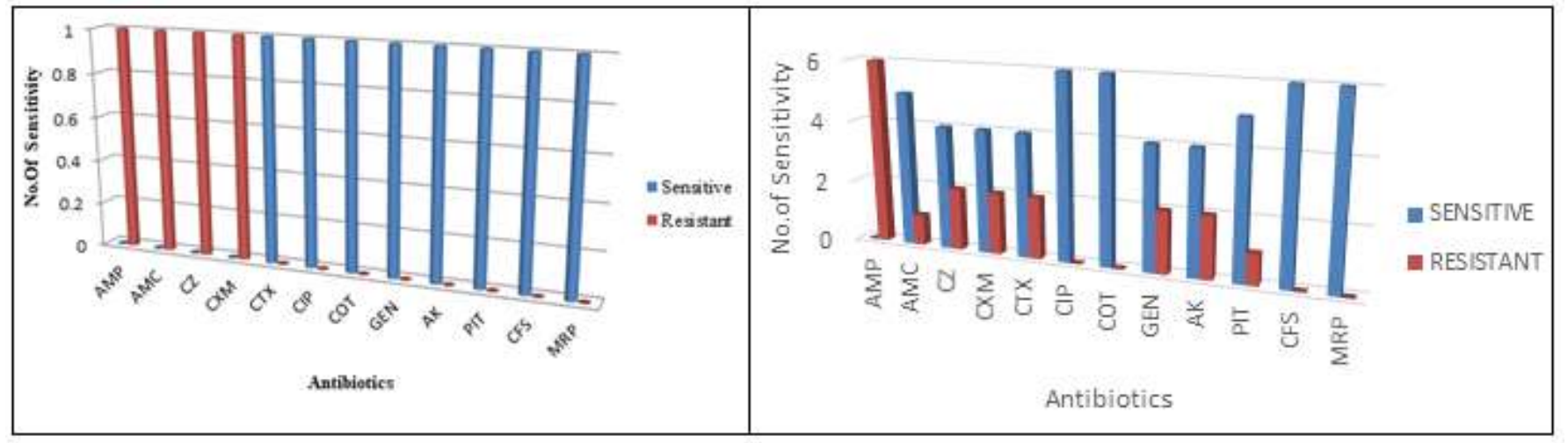

Figure 5: Antibiogram of Escherichia coli

Figure 6: Antibiogram of Klebsiella pneumoniae

AMP- Ampicillin, AMC- Amoxycillin/clavulanic acid, CZ-Cefazolin, CXM- Cefuroxime, CTX- Cefotaxime, CIP-Ciprofloxacin, COTCotrimoxazole, GEN- Gentamicin, AK-Amikacin, PIT- PiperacillinTazobactum, CFS- Cephoperazone + sulbactam, MRP- Meropenem 
Table 1: Sex Vs Isolation (\%)

\begin{tabular}{|c|c|c|}
\hline Sex & Frequency & Percentage (\%) \\
\hline Male & 18 & 62.060 \\
\hline Female & 11 & 37.93 \\
\hline Total & 29 & 100 \\
\hline
\end{tabular}

Table 2: Age Distribution

\begin{tabular}{ccc}
\multicolumn{3}{c}{ Table 2: Age Distribution } \\
\hline Age & Frequency & Percentage (\%) \\
\hline$<10$ Years & 18 & 62.06 \\
11-20 Years & 2 & 6.89 \\
21-30 Years & 3 & 10.34 \\
31- 40 Years & - & - \\
41-50 Years & - & - \\
51-60 Years & - & - \\
61-70 Years & - & - \\
71- 80 Years & 6 & 20.68 \\
\hline Total & 29 & 100 \\
\hline
\end{tabular}

Table 3: Monthly Distribution

\begin{tabular}{ccc}
\hline Month & Frequency & Percentage (\%) \\
\hline January & 3 & 10.34 \\
February & 5 & 17.24 \\
March & 1 & 3.44 \\
April & 2 & 6.89 \\
May & 4 & 13.79 \\
June & 1 & 3.44 \\
July & 4 & 13.79 \\
August & 3 & 10.34 \\
September & 3 & 10.34 \\
October & 1 & 3.44 \\
November & 1 & 3.44 \\
December & 1 & 3.44 \\
\hline Total & 29 & 100 \\
\hline
\end{tabular}

\section{DISCUSSION}

In this study the prevalence of bacteria among otitis media patients in the health care centre was $78.37 \%$. This finding coincides with the findings of Seid et al. 2013 and Muluye et al. 2013. The present study shows that males are more commonly affected than females. Male predominance may be because of their more exposed way of life. The report of Kiran et.al., 2019 is same that of this study. Less than 10 -year-old patients were significantly colonized by bacterial pathogen and this result is coinciding with the findings of Iseh and Adegbite 2004. Low immune status, shorter and horizontal nature of their Eustachian tubes, frequent exposure to upper respiratory tract infections and malnutrition could be the possible justifications for the high infection in this age group. The monthly reports of Otitis media was most common in February (17.24\%) and this findings are similar to the study done by Kiran et.al., 2019. The Gram-negative bacteria, $82.75 \%$ were the dominant isolates of the samples compared to Grampositive bacteria. Parallel reports were seen in the research documents of Abera and Kibret 2011 and Ferede et al.
2001). The bacteria Staphylococcus aureus, Proteus mirabilis and Pseudomonas aeruginosa, Klebsiella pneumoniae and Escherichia coli were the overriding isolates in this study. This was in line with finding from Addis Ababa (Ferede et al. 2001). Pseudomonas aeruginosa, was the dominant cause of OM in this study was reported as same that of Weckwerth et al. 2009. The disparity in climatic and geographic could be the probable reasons for the distinction in distribution of the bacteria. In this study monoclonal infection was seen in $100 \%$ of the patients. This observation was supported by other researchers like Ettehad et al. 2006. In contrast to this, other study from India is reported (Kumar and Seth 2011). The Prevalence of coliforms bacteria such as Proteus mirabilis, Klebsiella pneumonia and Escherichia coli in this study was tandem to reports by Prakash et al. 2013, Mansoor et al. 2009 and Shyamala and Reddy (2012). In vitro antimicrobial susceptibility pattern revealed that isolates were highly resistant to most antibiotics. Staphylococcus aureus were $100 \%$ resistant to Penicillin. This result was in line with that of study done Osazuwa et al. 2011 and Prakash et al. 2013. However Staphylococcus aureus isolates were less resistant for gentamicin, which was similar with the results of other researches Abera and Kibret 2011. Pseudomonas aeruginosa was sensitive to ciprofloxacin and this result is as same that of the findings of Yismaw et al. 2010 and Rao and Bhaskaran 1984". All isolates of $\mathrm{P}$. mirabilis were $100 \%$ sensitive to ciprofloxacin and this was in concurrence with Prakash et al. 2013.

\section{CONCLUSION}

Most of the isolates showed resistance to antimicrobial agents. However, bacterial isolates were sensitive to ciprofloxacin and gentamicin. This can be used in the treatment of otitis media. Early treatment of ear infection can play great role in management of otitis media and avoid further emergence of multi drug-resistant bacteria. Acknowledgement

The authors gratefully acknowledge the tremendous support and encouragement of Dr. J. Bennet Abraham (Director, Dr.S.M.C.S.I.M.C.and H.), Dr.SamsonNessaiah (Principal, Dr.S.M.C.S.I.M.C.and H.) and all other wellwishers for the successful completion of this research work.

\section{REFERENCE}

1. Abera B, Kibret M (2011) Bacteriology and antimicrobial susceptibility of otitis media at dessie regional health research laboratory, Ethiopia. Ethiopian J Health Develop 25(2):161-167

2. Cheesbrough M (2006) District laboratory practice in tropical countries part II, 2nd edn. Cambridge University Press, NewYork. 
3. CLSI. Performance Standards for Antimicrobial Susceptibility Testing. Clinical and Laboratory Standards Institute. 2016;39-43

4. Cockerill FR, Wikler MA, Bush K, Dudley MN, Eliopoulos GM, Hardy DJ, et al.. Performance Standards for Antimicrobial Susceptibility Testing Twenty-First Informational Supplement 2011.

5. Ettehad GH, Refahi S, Nemmati A, Pirzadeh A, Daryani A (2006) Microbial and antimicrobial susceptibility patterns from patients with chronic otitis media in Ardebil. Int $\mathrm{J}$ Trop Med. 1:62-65

6. Ferede D, Geyid A, Lulseged S et al. (2001) Drug susceptibility pattern of bacterial isolates from children with chronic suppurative otitis media. Ethiop J Health Dev 15(2):89-96

7. Gates GA, Klein JO, Lim DJ, Mogi G, Ogra PL, Pararella $\mathrm{MM}$, et al. . Recent advances in otitis media 1. Definitions, terminology, and classification of otitis media. Ann OtolRhinolLaryngolSuppl 2002;188:8-18

8. Iseh KR, Adegbite T (2004) Pattern and bacteriology of acute suppurativeotitismedia in Sokoto, Nigeria. Ann Afri Med 3(4):164-166

9. Jyothi.R, Samitha, Harilal, RamaniBai.J.T , Lancy.J, Aetiological Spectrum of Chronic Suppurative Otitis Media in a Tertiary Care Centre in Kerala. JMSCR Volume 05 Issue 10 October 2017; 29604-29613

10. Kiran Gopal, Jinu $\mathrm{T}$ Eldho, Mohammed Riyas. Bacteriology of chronic suppurative otitis media and its associated risk factors in a tertiary care hospital. MedPulse International Journal of Microbiology. November 2019; 12(2): 36-40.

11. Kumar H, Seth S (2011) Bacterial and fungal study of 100 cases of chronic suppurative otitis media. J ClinDiagn Res 5:1224-1227

12. Lee KS, Park CD, Kim GM, Boo HS, Choi JY, Byun YJ et al. (2012) Rate of isolation and trends of antimicrobial resistance of multidrug resistant PseudomonasAeruginosafrom otorrhea in chronic suppurative otitis media. ClinExpOtorhinolaryngol $5(1): 17-22$

13. Mansoor T, Musani MA, Khalid G, Kamal M (2009) Pseudomonas aeruginosain chronic suppurative otitis media: sensitivity spectrum against various antibiotics in Karachi. J Ayub Med Coll Abbottabad 21:120-123

14. Monasta L, et al. Burden of disease caused by otitis media: systematic review and global estimates. PLoS One. 2012;7(4)

15. Muluye D, Wondimeneh Y, Ferede G, Moges F, Nega T (2013) Bacterial isolate and drug susceptibility patterns of ear discharge from patients with ea infection at Gondar
University Hospital, Northwest Ethiopia. BMC Ear Nose and Throat Disord 13:10

16. O. A. Afolabi, A. G. Salaudeen, F. E. Ologe, C. Nwabuisi, and C. C. Nwawolo, "Pattern of bacterial isolates in the middle ear discharge of patients with chronic suppurative otitis media in a tertiary hospital in north central Nigeria," African Health Sciences, vol. 12, no. 3, pp. 362 368, 2012.

17. Osazuwa F, Osazuwa E, Osime C, Igharo EA, Imade PE et al. (2011) Etiologic agents of otitis media in Benin city, Nigeria. North Am J Med Sci 3:95-98

18. Prakash R, Juyal D, Negi V, Pal S, Adekhandi S et al. (2013) Microbiology of chronic suppurative otitis media in a tertiary care setup of Uttarakhand State, India. N Am J Med Sci 5(4):282-287

19. Rao R, Bhaskaran CS (1984) Bacteriology of chronic suppurative otitis media with special reference to anaerobes. Indian J PatholMicrobiol 27:341-346

20. Seid A, Deribe F, Ali K, Kibru G (2013) Bacterial otitis media in all age group of patients seen at Dessie referral hospital, North East Ethiopia. Egypt J Ear Nose Throat Allied Sci 14:73-78

21. Shyamla R, Reddy SP (2012) The study of bacteriological agents of chronic suppurative otitis media-aerobic culture and evaluation. J MicrobiolBiotechnol Res 2:152-162

22. Spellberg B, Guidos R, Gilbert D, Bradley J, Boucher HW, Scheld WM et al.. The epidemic of antibiotic-resistant infections: a call to action for the medical community from the Infectious Diseases Society of America. Clin Infect Dis. 2008; 46:155-64

23. Ullauri, A. Smith, M. Espinel, C. Jimenez, C. Salazar, and R. Castrillon, "WHO ear and hearing disorders survey: Ecuador national study 2008-2009," Conference Papers in Science, vol. 2014, Article ID 847526, 13 pages, 2014.

24. Weckwerth PH, Lopes CA, Duarte MA, Weckwerth AC, Martins CH et al. (2009) Chronic suppurative otitis media in cleft palate: microorganism etiology and susceptibilities. Cleft Palate Craniofac J 46(5):461-467

25. Woodfield G, Dugdale A. Evidence behind the WHO guidelines: hospital care for children: What is the most effective antibiotic regime for chronic suppurative otitis media in children? J Tropical Pediatric. 2008;54(3):151156.

26. World Health Organization, "Deafness and hearing loss," Fact Sheet 300, 2015, http://www. who.int/mediacentre/factsheets/fs300/en/.

27. Yismaw G, Abay S, Asrat D, Yifru S, Kassu A (2010) Bacteriological profile and resistance patterns of clinical isolates from pediatric patients, Gondar University teaching hospital. Gondar, Ethiopia. Ethiop Med J 48(4):293-299.

\section{Source of Support: None Declared Conflict of Interest: None Declared}

Policy for Articles with Open Access:

Authors who publish with MedPulse International Journal of Microbiology (Print ISSN: 2550-7648) (Online ISSN: 2636-4646) agree to the following terms: Authors retain copyright and grant the journal right of first publication with the work simultaneously licensed under a Creative Commons Attribution License that allows others to share the work with an acknowledgement of the work's authorship and initial publication in this journal.

Authors are permitted and encouraged to post links to their work online (e.g., in institutional repositories or on their website) prior to and during the submission process, as it can lead to productive exchanges, as well as earlier and greater citation of published work. 